\title{
Perancangan Multi Node Web Server Menggunakan Docker Swarm dengan Metode Highavability
}

\author{
Ahmad Rivaldi", Ucuk Darusalam, Deny Hidayatullah \\ Fakultas Teknologi Komunikasi dan Informatika, Teknik Informatika, Universitas Nasional, Jakarta, Indonesia \\ Email: 1,*ahmadrivaldi21@ gmail.com, ${ }^{2}$ ucuk.darusalam@gmail.com, ${ }^{3}$ deny @ civitas.unas.ac.id \\ Email Penulis Korespondensi: ahmadrivaldi21@gmail.com
}

\begin{abstract}
Abstrak-Virtualisasi berbasis container sangat popular dikalangan programming development di karenakan virtualisasi yang ringan dimana kernel Linux dapat membagi penggunakan resource antar container bertujuan agar kinerja tidak saling terganggu antar lainnya serta sebagai pembagi beban dalam menanggulangi banyaknya bandwith yang masuk. Salah satu virtualisasi berbasis container yang sering digunakan adalah Docker. Docker sendiri merupakan open source software yang dapat di ubah sesuai dengan keinginan. Container Docker dapat digunakan untuk clustering web server. Hal ini bertujuan untuk mengurangi "a single point of failure" (SPOF) dalam web server. Bagaimanapun mengatur container dalam jumlah banyak sangatlah rumit, tetapi Docker memiliki engine untuk mengaturnya yang disebut Docker Swarm. Dengan di bantu management NGINX sehingga dapat mengakibatkan resource antar host tidak terbagi secara rata. Oleh karena itu penelitian ini bertujuan untuk mendistribusikan traffic web server secara rata antar host dengan loadbalancing berdasarkan sumber daya monitoring dan failover berdasarkan waktu. Dengan memenfaatkan rendahnya resource atau sumber daya yang di gunakan oleh docker dalam pengoperasian sebuat aplikasi yang dapat di virtualisasikan hanya apa yang di butuhkan.
\end{abstract}

Kata Kunci: Docker, load balancer, swarm, web cluster

Abstract-Container-based virtualization is very popular among programming development in a lightweight virtualization because where the Linux kernel can divide resource-using containers to prevent uninterrupted performance between And as a burden divider in tackling the many incoming bandwidth. One of the most commonly used container-based virtualization is Docker. Docker itself is an open source software that can be changed to your liking. Docker containers can be used for clustering Web servers. It aims to reduce "a single point of failure" (SPOF) in a Web server. However, arranging a lot of containers is very complicated, but Docker has an engine to set it up called Docker Swarm. With it in the NGINX management help so that it can cause the resource between hosts is not divided on average. Therefore the research aims to distribute Web server traffic across the host with loadbalancing based on time-based monitoring and failover resources. By winning the low resources or resources used by Docker in the operation of an application that can be virtualized only what is needed.

Keywords: Docker, Load Balancers, Swarm, Web Clusters.

\section{PENDAhUluan}

Seiring dengan perkembangan teknologi komputer yang sangat pesat salah satunya pada bidang jaringan virtualisasi web server, system administrator ditantang untuk membuat sebuah sistem virtualisasi yang mengkombinasikan antara fleksibilitas dan penggunaan sumber daya yang minimum untuk proses kemudahan deployment (penyebaran) [1]. Teknik virtualisasi adalah teknik dimana mengisolasi suatu sistem sehingga tidak mengganggu sistem yang lainnya. Salah satu teknik virtualisasi adalah virtualisasi berbasis container. Virtualisasi berbasis container adalah teknik yang tidak menerapkan Hypervisior yang hanya mengisolasi proses tanpa mengisolasi perangkat keras, kernel dan operating system sehingga dapat mengurangi overhead pada hardware juga performanya lebih baik darii virtulasi mesin [2]. Teknologi virtualisasi memiliki beberapa perangkat lunak yang sering digunakan seperti proxmox, vmware, xen, virtualbox, dan hyper-v, perangkat lunak tersebut adalah jenis hypervisor. Hypervisor adalah sebuah teknik virtualisasi yang memungkinkan beberapa operating system untuk berjalan bersamaan pada sebuah host, hypervisor memiliki dua kategori native hypervisor dan hosted hypervisor, native hypervisor merupakan virtual machines yang berjalan atau diinstal langsung pada hardware atau PC seperti proxmox, vmware ESX, dan hyper-v, sedangkan hosted hypervisor adalah virtual machines yang diinstal diatas operating system atau OS yang kemudian guest OS berjalan pada proses aplikasi virtual machines tersebut seperti virtual box, vmware player, parallels desktop dan qети [3]. Salah satu virtualisasi yang berbasis container adalah Docker.

Docker adalah open platform yang memungkinkan sebuah service dalam environment terisolasi, yang bisa disebut dengan container [4]. Sebuah container dapat mengemas library maupun dependency yang dibutuhkan oleh suatu layanan (aplikasi), sehingga share kernel memungkinkan berbagi library dan dependency yang dibutuhkan, dan sebuah layanan (aplikasi) dapat dijalankan tanpa harus menghidupkan guest $O S$ terlebih dahulu, proses tersebut dihilangkan, sehingga kebutuhan resource (CPU, RAM) berkurang dan waktu yang dibutuhkan untuk menjalankan layanan semakin cepat [2,5]. Salah satu teknik untuk mengatasi masalah tersebut adalah menggunakan teknik web cluster. Teknik ini adalah menggunakan beberapa mesin dapat berupa virtualisasi host atau host asli lebih dari satu dalam satu jaringan yang saling terhubung. Jika salah satu host mati maka terdapat host lainnya untuk menangani request dari client sehingga tercapai fungsi ketersediaan (availability) [8]. Bagaimanapun mengatur banyak host sangatlah kompleks, tetapi Docker memiliki modul untuk menangani masalah tersebut yang disebut Docker Swarm. 
Load balancer terbagi menjadi 2 yaitu loadbalancer software dan hardware. Terdapat banyak software load balancing diantaranya yaitu HAproxy, Nginx, dan Zevenet. Pada penelitian sebelumnya yang berjudul "Load Balancing Server Web Berdasarkan Jumlah Koneksi Klien Pada Docker Swarm" bahwa load balancing pada Nginx dapat diterapkan pada Docker Swarm (Dimas Setiawan Afis, 2018). Kelebihan menggunakan Nginx dalam Docker adalah terdapat modul load balancer yang tersedia langsung di dalamnya sehingga mengurangi penggunaan resource pada host dan ketergantungan modul lainnya. Nginx terdapat pada repository Docker yang telah di package menjadi container sehingga mudah untuk di implementasikan[9].

Dari referensi diatas dapat disimpulkan bahwa penggunaan load balancing dapat mengoptimalkan suatu web server dengan membagi beban traffic dengan berbagai algoritma dan metode yang berbeda. Oleh karena itu, peneliti menggunakan metode load balancing berbasis sumber daya metode ini dipilih karena dengan mengetahui penggunaan memory web server kita bisa mengetahui Node worker mana yang bebannya sedikit memproses suatu request sehingga beban dapat didistribusikan dengan baik dan dapat mendeteksi host yang down ketika bekerja. Serta kemudahan dan fleksibilitas yang di tawarkan juga sangat menguntunkan para developer dan user sebagai pengguna dengan minimnya resource yang di punya perangkatnya. Dengan virtualisasi yang menghasilkan peningkatan kinerja dari docker, dapat menghemat sumber daya yang di gunakan, dan dengan adanya load balancing yang dapat meringankan kinerja server sebagai penyedia sumber daya perangkat. Metode ini juga dapat di terapkan sebagai online library dan repository yang dapat mengurangi kinerja server ketika access user sedang peak. Ada beberapa hal yang menunjang untuk lebih majunya trend virtualisasi. Dengan semakin banyaknya physical server juga akan semakin banyak sumber tenaga listrik yang digunakan, ini juga yang membuat semakin populernya virtualisasi.

\section{METODOLOGI PENELITIAN}

Penelitian ini berfokus pada meringankan sumber daya yang digunakan oleh server host dengan metode virtualisasi yang berbeda dengan biasanya disediakan oleh beberapa aplikasi seperti proxmox, virtualbox, vmware, dll. Dengan rendahnya sumber daya yang digunakan dapat menunjang kinerja server sebagai perangkat multitasking. Dibawah ini diberikan perbandingan yang dikutip dari jurnal sebelumnya ketika menggunakan virtualisasi selain Docker. Pemanfaatan serta peningkatan kapabilitas di sisi pengguna yang juga sangat menguntungkan dengan rendahnya sumber daya yang terpakai.

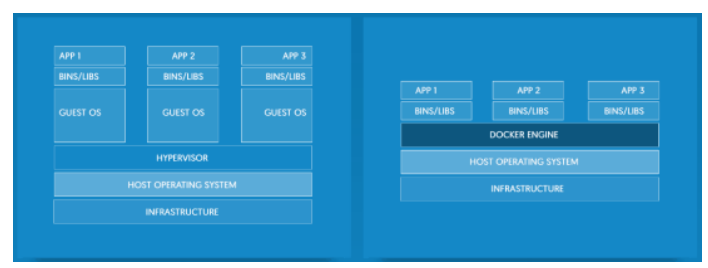

Gambar 1. Tabel Perbandingan

Dapat dilihat dari tabel perbandingan antara docker dan virtualbox dalam menjalankan virtualisasi sebuah aplikasi atau system operasi. Di virtualbox ketika membutuhkan sebuah aplikasi yang akan dijalankan di guest OS, diperlukan instalasi untuk guest $O S$ tersebut. Berbeda dengan docker yang hanya divirtualisasikan binary yang terkait oleh aplikasi atau system operasi yang akan dijalankan dan dapat meringankan kinerja host serta infrastruktur.

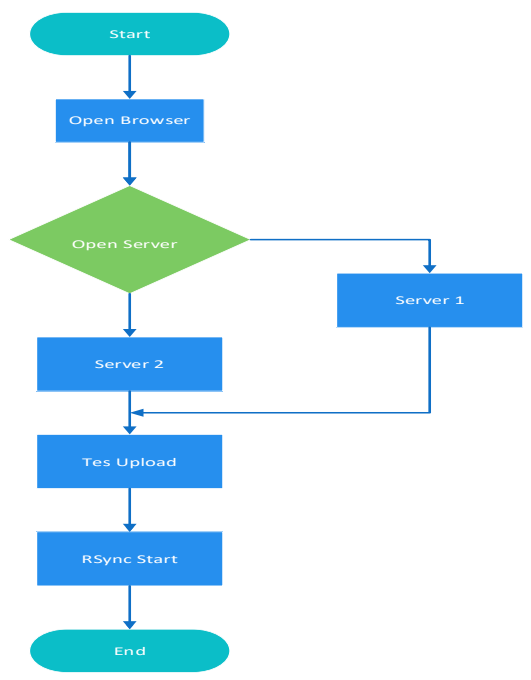

Gambar 2. Flowchart Upload 
JURNAL MEDIA INFORMATIKA BUDIDARMA

Volume 4, Nomor 3, Juli 2020, Page 529-534

ISSN 2614-5278 (media cetak), ISSN 2548-8368 (media online)

Available Online at https://ejurnal.stmik-budidarma.ac.id/index.php/mib

DOI 10.30865/mib.v4i3.2147

Flowchart diatas sebagai gambaran untuk memberikan penjelasan proses berjalannya upload data ke server menggunakan docker. Dimulai dari user membuka browser, setelah itu akan tampil halaman home browser , kemudian user melakukan upload data. Setelah user upload data di server, sistem melakukan RSync yang artinya data yang tadi di upload oleh user di sinkronasikan ke server berikutnya. RSync adalah tools yang berfungsi untuk memindahkan dan mensinkronisasikan file secara efektif antara perangkat lokal, remote server, atau perangkat lainnya yang serupa. Bagi user sistem berbasis Linux, command ini sangat disarankan karena memungkinkan mereka untuk mengatur dan mengelola file atau direktori. Sinkronisasi folder atau penyalinan file secara manual akan sangat membuang-buang waktu. Rsync dapat melakukan banyak hal, termasuk menambahkan beberapa fitur canggih untuk menghemat waktu. Bahkan jika koneksi hilang saat memindahkan file, tools ini akan memulai dari proses pemindahan yang sempat terhenti ketika koneksi sudah kembali.

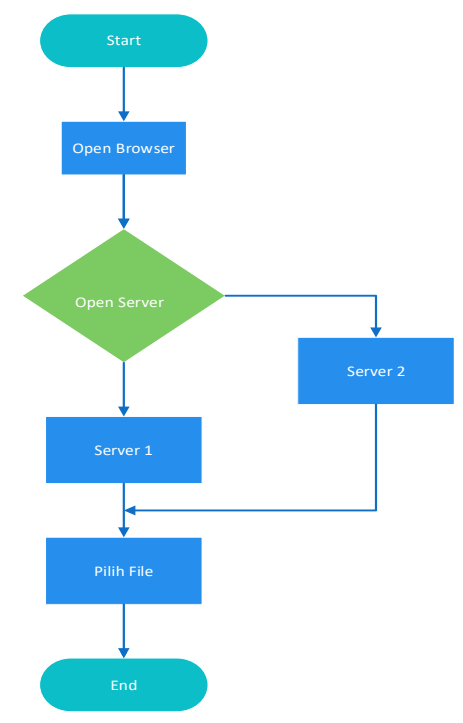

Gambar 3. Flowchart Download

Flowchart diatas sebagai gambaran untuk memberikan penjelasan cara download data dari server menggunakan docker. Dimulai dari user membuka browser dilanjutkan dengan muncul tampilan halaman home yang berisi datadata yang ada di server. Setelah itu, user mendownload data tersebut. Jika dalam mendownload data yang ada di server kemudian ada user lain mendownload data yang ada di server tersebut dengan berbarengan, maka user tersebut akan mendownload dari server yang satunya.

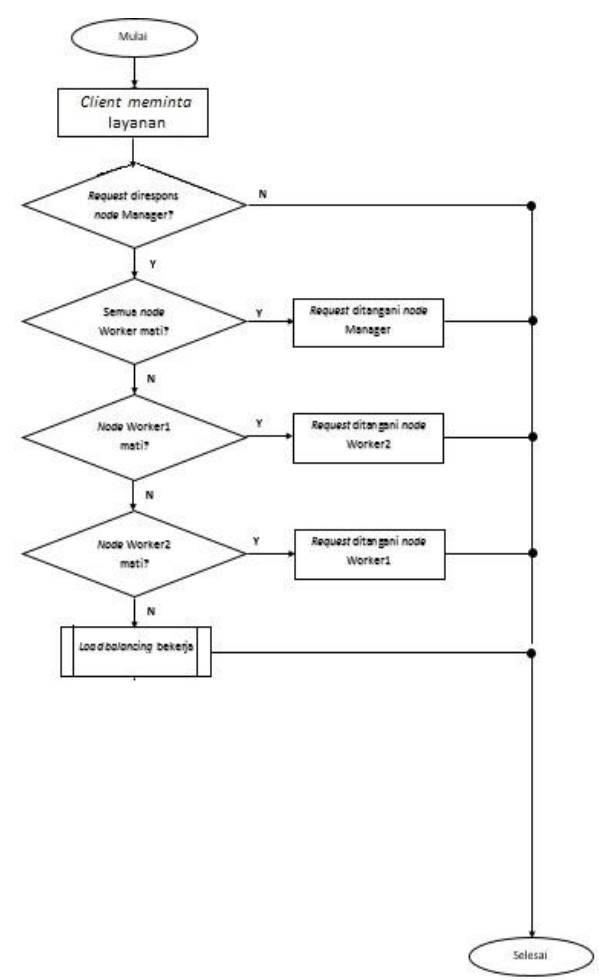

Gambar 4. Flowchart Perancangan 
JURNAL MEDIA INFORMATIKA BUDIDARMA

Volume 4, Nomor 3, Juli 2020, Page 529-534

ISSN 2614-5278 (media cetak), ISSN 2548-8368 (media online)

Available Online at https://ejurnal.stmik-budidarma.ac.id/index.php/mib

DOI 10.30865/mib.v4i3.2147

Dari gambar flowchart diatas ini adalah cara kerja dari perancangan ini, dimana pada saat client meminta layanan atau akses itu akan dialihkan ke dalam Nginx node manager. Node manager yang berupa aplikasi Nginx akan meneruskan request untuk melihat server mana yang sedang hidup serta dengan penggunaan memory terendah agar tidak membebani server yang sedang melakukan proses untung melayani kebutuhan $u s e r$. Dengan alur kerja seperti ini tingkat pembenan terhadap server akan di bagi jadi beberapa titik tidak berpusat sehingga dapat membuat path yang lebih cepat dan responsive.

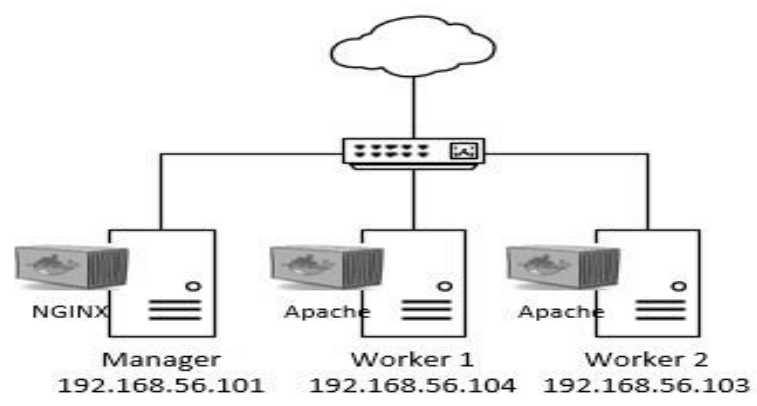

Gambar 5. Topology Yang Digunakan

Ini adalah bagaimana topology yang akan di gunakan dalam penelitian ini. Ada 3 komponen utama yaitu manager sebagai pembagi pembebanan dan worker sebagai urldir app server. Semua interkoneksi yang di terima akan melalui manager baru di teruskan ke masing masing worker. Pembagian pembebanan itu juga di konfigurasi di node manager.

\section{HASIL DAN PEMBAHASAN}

Setelah penulis melakukan rangkaian pengujian pada 3 buah perangkat sebagai client yang terdiri dari user 1 adalah laptop yang mendownload menggunakan software pihak ketiga yaitu Internet Download Manager (IDM), dan user 2 adalah handphone yang berjumlah 2 unit handphone yang mendownload menggunakan aplikasi Google Chrome. Ketiga perangkat tersebut, masing-masing melakukan download file berkapasitas 8,8 GB yang ada di server. Dibawah ini adalah timestep dari hasil pengujian yang dilakukan secara serentak :

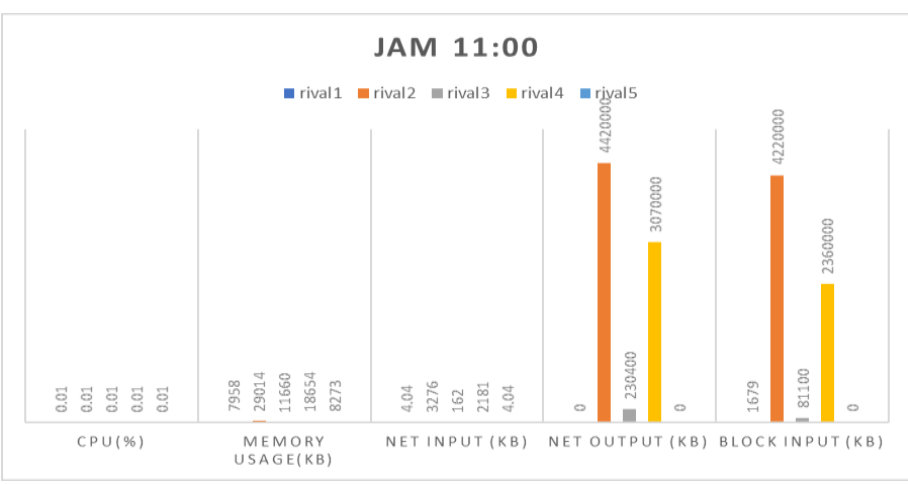

Gambar 6. Timestep pertama

Gambar 6 menjelaskan tentang timestep usage server yang sedang digunakan ketika download file. Pada gambar di atas, menunjukkan terdapat 5 server yang ke lima-limanya berjalan bersamaan. Pada grafik di atas penggunaan usage pada rival1, rival2, rival3, rival4 dan rival5 CPU, Memory Usage, Net Input, Net Output, Block Inputnya masih relative rendah.

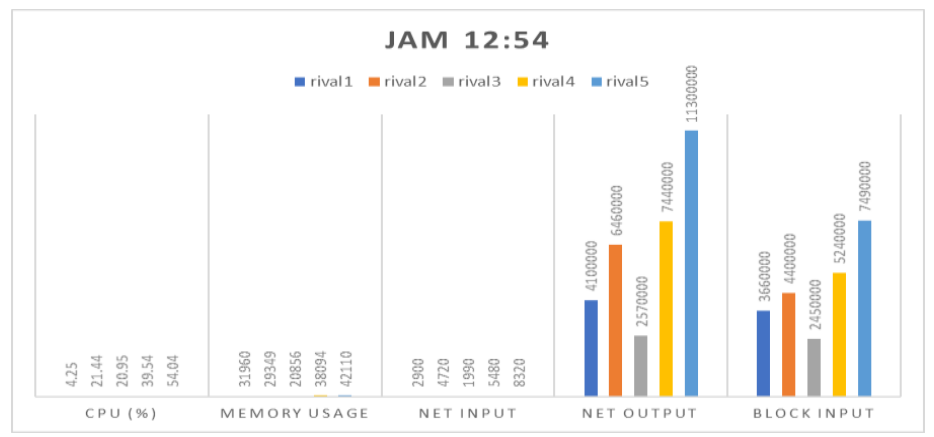

Gambar 7. Timestep kedua 
JURNAL MEDIA INFORMATIKA BUDIDARMA

Volume 4, Nomor 3, Juli 2020, Page 529-534

ISSN 2614-5278 (media cetak), ISSN 2548-8368 (media online)

Available Online at https://ejurnal.stmik-budidarma.ac.id/index.php/mib

DOI 10.30865/mib.v4i3.2147

Gambar 7 menunjukkan adanya peningkatan traffic pada Net Output dan Block Input. Sedangkan pada CPU, Memory Usage dan Net Input usage yang digunakkan masih rendah.

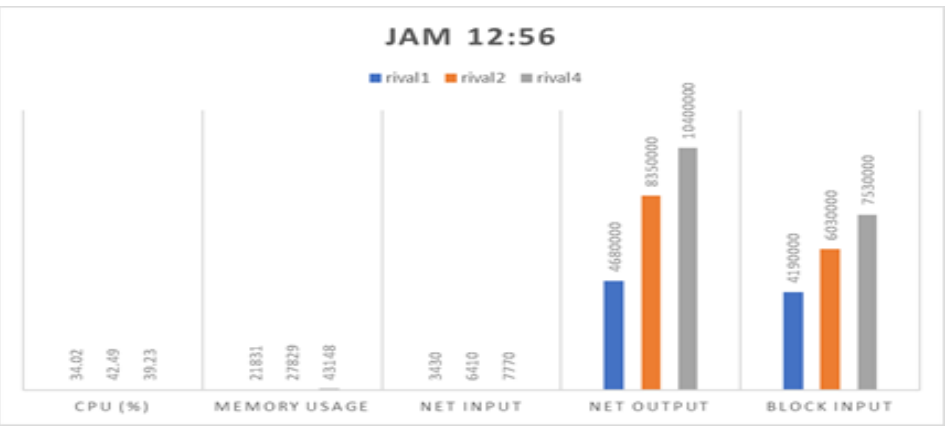

Gambar 8. Timestep ketiga

Gambar 8 menjelaskan uji coba menggunakan 3 server. Pada grafik di atas terdapat kenaikan penggunaan usage server yang signifikan pada Net Output dan Block Input.

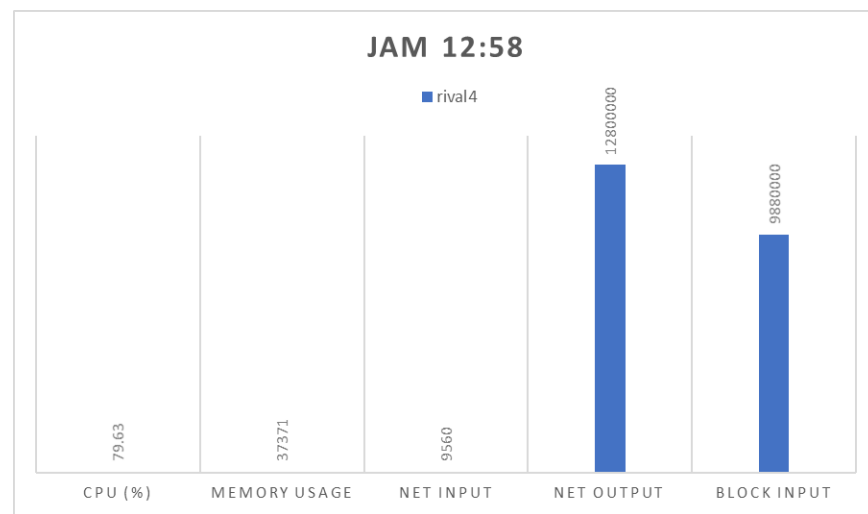

Gambar 9. Timestep keempat

Gambar 9 menjelaskan uji coba menggunakan 1 server. Dan terlihat pada grafik tersebut usage Net Output dan Block Input masih sangat tinggi. Pada pengujian di atas, nilai penggunaan resource yang didapat dengan menggunakan aplikasi Docker Start dan ntop yang terpakai pada server. Semakin kecil jumlah penggunaan resource, maka semakin baik sistem tersebut dan juga semakin ringan sistem tersebut untuk dijalankan pada server. Pada pengujian di atas terlihat bahwa satu host menggunakan jumlah resource lebih tinggi dibanding dengan sistem yang menggunakan lima host pada server. Hal tersebut disebabkan karena penggunaan dalam single server mendapatkan beban kerja yang jauh lebih tinggi dibandingkan dengan menggunakan algoritma Upstream Module, Weight, Hash, dan Max Fails. Terjadi penurunan pada sistem load balancing dengan menggunakan algoritma Upstream Module, Weight, Hash, dan Max Fails karena beban kerja dibagi secara merata pada server lainnya dan tidak terpusat pada satu buah web server. Maka menggunakan web server cluster pada virtualisasi container docker akan meghemat penggunaan resource yang ada.

\section{KESIMPULAN}

Berdasarkan pengujian yang dilakukan, dapat disimpulkan bahwa:

1. Performa dan kemampuan load balancing dengan lima buah web server cluster dalam melayani request client jauh lebih bak dibandingkan single server, karena mengacu pada konsep cluster computing dimana penggunaan cluster dalam sebuah server tidak membebankan atau terpusat pada satu server saja sehingga tidak memberatkan server.

2. Pada sistem load balancing Nginx, algoritma Upstream Module berguna untuk menyeimbangkan penggunaan sumber daya atau resource server yang digunakan. Algoritma Weight melakukan perhitungan perbedaan kemampuan processing dari masing-masing server anggota cluster. Administrator memasukan secara manual parameter beban yang akan ditangani oleh masing-masing server anggota cluster, kemudian scheduling sequence secara otomatis dilakukan berdasarkan beban server. Algoritma IP Hash ini akan mendistribusikan traffic berdasarkan IP dari client. Nginx akan mencocokkan web server backend dengan IP yang dimiliki oleh client, sehingga apabila seorang client mendapatkan respone dari rival1 pada pertama kali, maka request selanjutnya juga akan mendapat respone dari rival1 dan seterusnya sampai server tersebut dianggap down. Jika down, maka client akan diarahkan ke rival2 dan seterusnya. Algoritma Max Fails adalah parameter untuk mengindikasikan berapa kali server tersebut diberi kesempatan jika terjadi gagal respon. Dan Max Fails akan 


\section{JURNAL MEDIA INFORMATIKA BUDIDARMA}

Volume 4, Nomor 3, Juli 2020, Page 529-534

ISSN 2614-5278 (media cetak), ISSN 2548-8368 (media online)

Available Online at https://ejurnal.stmik-budidarma.ac.id/index.php/mib

DOI 10.30865/mib.v4i3.2147

dihitung apabila sudah melampaui batas timeout sejak server tersebut gagal merespon. Apabila Max Fails sudah tercapai maka Nginx akan menganggap server tersebut down yang kemudia Nginx akan mengarahkan client ke server lain dan mengantisipasi agar tidak ada request client yang mengarah ke server tersebut. Nginx akan tetap mencoba untuk memberikan request ke server tersebut, apabila sudah mendapat respone kembali maka client yang diarahkan ke server lain akan diarahkan kembali ke server tersebut.

3. Dengan menggunakan berbagai macam metode yang dapat digunakan untuk membantu membagi pembebanan pada setiap server, akan dapat mempengaruhi kinerja pada setiap server. Kinerja yang di hasilkan dari metode pembagian pembebanan yang beragam dapat menghasilkan pemrosesan yang lebih cepat.

\section{REFERENCES}

[1] Chung, M. T., Quang-Hung, N., Nguyen, M. T., \& Thoai, N. (2016, July). Using docker in high performance computing applications. In Communications and Electronics (ICCE), 2016 IEEE Sixth International Conference on (pp. 52-57). IEEE.

[2] Adiputra, F. (2015). Container dan Docker teknik Virtualisasi dalam Pengelolaan Banyak Aplikasi Web.

[3] Jurenka, V. (2015). Virtualization using Docker Platform. Faculty of Informatics Masaryk University.

[4] Liu, D. \&. (2014). The Research and Implementation of Cloud Computing Platform Based on Docker.

[5] Bik, M. F. (2017). Implementasi Docker Untuk Pengelolaan Bayak Aplikasi Web. Universitas Negri Surabaya.

[6] Fateh, J. R. (2018). Implementasi Web Server Dengan Pemanfaatan Virtualisasi Docker.

[7] Mohammad, R. M. (2019). Implementasi Load Balancing Server Web Berbasis Docker Swarm Berdasarkan Penggunaan Sumber Daya Memory Host.

[8] Singh, H. (2015). WSQ: Web Server Queueing Algorithm for Dynamic Load Balancing.

[9] NGIX Software.INC. (2014, January 1). NGIX. (NGIX Software.INC) Retrieved February 15, 2018, from NGIX:https://www.nginx.com/blog/.

[10] M. Aldi Aditia Putra. (2020). Implementasi High Availability Cluster Web Server Menggunakan Virtualisasi Container Docker.

[11] D. S. Afis, M. Data, dan W. Yahya, "Load Balancing Server Web Berdasarkan Jumlah Koneksi Klien Pada Docker Swarm,"vol. 3, no. 1, hal. 925-930, 2019.

[12] T. P. Kusuma, R. Munadi, dan D. D. Sanjoyo, "Implementasi dan Analisis Computer Clustering System dengan Menggunakan Virtualisasi Docker," e-Proceeding Eng., vol. 4, no. 3, hal, 1-6, 2017.

[13] Dwi S. H. (2016). Perancangan Virtualisasi Sistem Operasi Dengan Menggunakan Docker Berbasis Terminal Emulator Untuk Peningkatan Performa. 